\title{
Regional Heterogeneity for the Intracranial Self-Administration of Ethanol and Acetaldehyde within the Ventral Tegmental Area of Alcohol-Preferring (P) Rats: Involvement of Dopamine and Serotonin
}

\author{
Zachary A Rodd*,', Richard L Bell', Ying Zhang ${ }^{1,3}$, James M Murphy',3, Avram Goldstein 4 , \\ Alejandro Zaffaroni ${ }^{5}$, Ting-Kai $\mathrm{Li}^{6}$ and William J McBride ${ }^{1,2}$ \\ 'Department of Psychiatry, Institute of Psychiatric Research, Indiana University-Purdue University at Indianapolis, Indianapolis, IN, USA; \\ ${ }^{2}$ Department of Biochemistry, Indiana University School of Medicine, Indiana University-Purdue University at Indianapolis, Indianapolis, IN, USA; \\ ${ }^{3}$ Department of Psychology, Purdue School of Science, Indiana University-Purdue University at Indianapolis, Indianapolis, IN, USA; ${ }^{4}$ Stanford \\ University, Stanford, CA, USA; ${ }^{5}$ Technofyn Associates, Palo Alto, CA, USA; ${ }^{6}$ NIAAA, Bethesda, MD, USA
}

\begin{abstract}
The meso-limbic dopamine (DA) system has an important role in regulating alcohol drinking. Previous findings from our laboratory indicated that Wistar rats self-administered ethanol $(\mathrm{EtOH})$ directly into the posterior, but not anterior, ventral tegmental area (VTA), and that coadministration of a $\mathrm{DA} \mathrm{D}_{2,3}$ receptor agonist or a serotonin-3 $\left(5-\mathrm{HT}_{3}\right)$ receptor antagonist blocked EtOH self-administration In addition, we reported that alcohol-preferring $(P)$ rats self-administered acetaldehyde (ACD), the first metabolite of EtOH, into the posterior VTA. The objectives of this study were to compare the reinforcing effects of EtOH and ACD within the VTA of $P$ rats to examine the possibility that the reinforcing effects of $\mathrm{EtOH}$ within the VTA may be mediated by its conversion to ACD. Adult female $P$ rats were stereotaxically implanted with guide cannulae aimed at either the posterior or anterior VTA. At I week after surgery, rats were placed in standard two-lever (active and inactive) experimental chambers for a total of seven to eight sessions. The 4-h sessions were conducted every other day. The results indicated that (a) 75-300 mg\% (17-66 mM) EtOH and 6-90 $\mu$ M ACD were self-administered into the posterior, but not anterior, VTA; (b) the self-administration of $150 \mathrm{mg} \% \mathrm{EtOH}$ was not altered by coinfusion of a catalase inhibitor; (c) coadministration of the $\mathrm{D}_{2 / 3}$ agonist quinpirole ( $100 \mu \mathrm{M}$ ) blocked the self-infusions of I $50 \mathrm{mg} \% \mathrm{EtOH}$ and $23 \mu \mathrm{M}$ ACD into the posterior VTA; and (d) coadministration of $200 \mu \mathrm{M}$ ICS205,930 (5- $\mathrm{HT}_{3}$ receptor antagonist) prevented the self-infusion of I $50 \mathrm{mg} \%$ $\mathrm{EtOH}$, whereas concentrations of ICS 205,930 up to $400 \mu \mathrm{M}$ had no effect on the self-infusion of $23 \mu \mathrm{M}$ ACD into the posterior VTA. Overall, the results of this study indicate that EtOH and ACD can independently produce reinforcing effects within the posterior VTA, and that activation of DA neurons mediates these effects. Furthermore, activation of $5-\mathrm{HT}_{3}$ receptors within the posterior VTA is involved in the self-infusion of EtOH, but not ACD.
\end{abstract}

Neuropsychopharmacology (2005) 30, 330-338, advance online publication, 22 September 2004; doi: I 0. I 038/s..npp. I 30056 I

Keywords: ventral tegmental area; intracranial self-administration; ethanol reinforcement; acetaldehyde reinforcement; serotonin-3 receptor; dopamine D2 receptor

\section{INTRODUCTION}

The meso-limbic dopamine (DA) system plays an important role in mediating the rewarding effects of ethanol (EtOH) and alcohol-drinking behavior (for review see Koob et al, 1998). Previous studies indicated that Wistar rats self-

\footnotetext{
*Correspondence: Dr ZA Rodd, Indiana University School of Medicine, Institute of Psychiatric Research, 79I Union Drive, Indianapolis, IN 46202-4887, USA, Tel: + | 317278 3003, Fax: + I 317274 |365,

E-mail: zrodd@iupui.edu

Received 4 March 2004; revised 27 July 2004; accepted 5 August 2004 Online publication: 10 August 2004 at http://www.acnp.org/citations/ NPP08100404102/default.pdf
}

administered $150-250 \mathrm{mg} \%$ EtOH directly into the posterior ventral tegmental area (VTA), whereas these concentrations were not self-infused into the anterior VTA (Rodd-Henricks et al, 2000). Furthermore, the intracranial self-administration (ICSA) of EtOH into the posterior VTA of Wistar rats was blocked with coinfusion of serotonin-3 $\left(5-\mathrm{HT}_{3}\right)$ receptor antagonists (Rodd-Henricks et al, 2003) or the DA $\mathrm{D}_{2,3}$ agonist quinpirole (Rodd et al, 2004b), suggesting the involvement of local $5-\mathrm{HT}_{3}$ receptors and VTA-DA neurons in the reinforcing effects of EtOH. In a subsequent study, the ICSA of EtOH into the posterior VTA was compared between alcohol-preferring $(\mathrm{P})$ and Wistar rats (Rodd et al, 2004a). The results of this latter study indicated 
that concentrations of $75-250 \mathrm{mg} \%$ EtOH were self-infused by $\mathrm{P}$ rats into the posterior VTA, suggesting that, compared to Wistar rats, the posterior VTA of $\mathrm{P}$ rats is more sensitive to the reinforcing effects of EtOH. However, the anteriorposterior subregional heterogeneity for the reinforcing effects of EtOH was not examined in the $\mathrm{P}$ rat. In addition, pharmacological studies to determine the involvement of $\mathrm{D}_{2}$ and $5-\mathrm{HT}_{3}$ receptors in mediating $\mathrm{EtOH}$ self-infusions, similar to those conducted with Wistar rats (Rodd et al, 2004b; Rodd-Henricks et al, 2003), have not been undertaken with $\mathrm{P}$ rats.

Acetaldehyde (ACD), the first major metabolite of EtOH, is a very active biological compound. Many behavioral and pharmacological effects of EtOH have been hypothesized to be mediated by ACD formed in the CNS (Aragon and Amit, 1992; Aragon et al, 1986; Smith et al, 1984, 1997). Because of the very low alcohol dehydrogenase activity in the brain (Aragon et al, 1992; Gill et al, 1992), it is unlikely that ACD is formed by this pathway in brain tissue. Moreover, under physiological conditions, the ACD formed peripherally from $\mathrm{EtOH}$ is not likely to enter the brain because of the high aldehyde dehydrogenase activity associated with the bloodbrain barrier (Smith et al, 1997; Sippel 1974; Zimatkin, 1991). However, there is evidence that ACD can be formed in brain tissue via a catalase reaction (Aragon et al, 1992; Hamby-Mason et al, 1997). Several pharmacological studies suggested that the effects attributed to EtOH might result from the formation of ACD through the catalase pathway (Aragon and Amit, 1992; Aragon et al, 1986; Brown et al, 1979; Smith et al, 1984, 1997). For example, inhibition of catalase activity decreases EtOH intake in Long-Evans rats (Aragon and Amit, 1992). Brown et al (1979) reported that rats self-administered 1-5\% ACD into the cerebral ventricles, and Smith et al (1984) found that repeated intracerebroventricular injections of ACD produced conditioned place preference. An ICSA study (Rodd-Henricks et al, 2002b), demonstrated that ACD was self-administered directly into the posterior VTA by $\mathrm{P}$ rats at concentrations that were 1000-fold lower than that for EtOH. The results of this latter study supported the idea that the pharmacological effects of $\mathrm{EtOH}$ in the CNS may result, at least partly, from the formation of ACD. If the self-infusion of EtOH within the VTA is due to its conversion to ACD, then blocking ACD formation should reduce the ICSA of EtOH. In addition, if $\mathrm{ACD}$ is producing the reinforcing effects attributed to $\mathrm{EtOH}$, then the mechanisms underlying the self-infusion of EtOH and ACD should be similar. Therefore, experiments to compare the effects of a $D_{2 / 3}$ agonist and a $5-\mathrm{HT}_{3}$ antagonist on the self-infusion of EtOH and ACD into the VTA were undertaken in the present study.

The hypothesis to be tested is that the reinforcing effects of EtOH within the VTA are mediated in part by its conversion to ACD. Several experiments were designed to test this hypothesis. In one experiment, the self-infusions of EtOH and ACD within the anterior and posterior VTA of $\mathrm{P}$ rats were compared. If the formation of ACD underlies EtOH selfinfusion, then ACD should be infused in the same subregions of the VTA as EtOH and at much lower concentrations. A second experiment attempted to reduce the formation of ACD from EtOH by coadministering 3-amino-1,2,4-triazole (triazole), a catalase inhibitor (Cohen et al, 1980; Koechling and Amit, 1994), and examined the effects on the self- infusion of EtOH into the posterior VTA. Additional experiments examined whether the reinforcing effects of ACD within the VTA are mediated by mechanisms similar to those supporting the reinforcing effects of $\mathrm{EtOH}$, that is, did ACD self-infusion also require activation of VTA DA neurons and local 5- $\mathrm{HT}_{3}$ receptors (Rodd et al, 2004b; Rodd-Henricks et al, 2003). If the formation of ACD underlied the reinforcing effects of EtOH within the VTA, then ACD self-infusion should be regulated in a manner similar to that for $\mathrm{EtOH}$.

\section{MATERIALS AND METHODS}

\section{Animals}

Alcohol- and experimentally naïve female alcohol-preferring $(\mathrm{P})$ rats weighing 250-320 g at the time of surgery were used. Rats were double-housed upon arrival and maintained on a 12-h reverse light-dark cycle (lights off at $0900 \mathrm{~h}$ ). Female $\mathrm{P}$ rats were used in the present study because they maintain their body and head size better than male $\mathrm{P}$ rats for more accurate and reliable placements. Although it is possible to delineate the anterior and posterior VTA in male $P$ rats, small variations in skull thickness and shape (which appear to be greater in male than female $\mathrm{P}$ rats) require readjusting coordinates from animal to animal with male $\mathrm{P}$ rats; this increases the surgery time and reduces reproducibility in the placements. Shortening the surgical times and increasing the reproducibility of placements are important considerations when large numbers of animals are used, comparisons across groups are being conducted, and highly accurate placements are required. Most of our previous ICSA studies used female rats (Ikemoto et al, 1997a, b; Gatto et al, 1994; Rodd-Henricks et al, 2000, 2002a,b, 2003). Although not systematically studied, the estrous cycle did not appear to significantly alter self-administration behavior, as indicated by fairly stable responding across several sessions, when the same concentration of EtOH (RoddHenricks et al, 2003) or ACD (Rodd-Henricks et al, 2002b) was given. Furthermore, a significant gender effect for the self-infusion of EtOH was not observed in a recent study using male Wistar rats (Rodd et al, 2004b).

Food and water were freely available except in the test chamber. Animals used in this study were maintained in facilities fully accredited by the Association for the Assessment and Accreditation of Laboratory Animal Care (AAALAC). All research protocols were approved by the institutional animal care and use committee and are in accordance with the guidelines of the Institutional Care and Use Committee of the National Institute on Drug Abuse, $\mathrm{NIH}$, and the Guide for the Care and Use of Laboratory Animals (National Research Council, 1996).

The number of animals indicated for each experiment represents $95 \%$ of the total number that underwent surgery; $5 \%$ of the animals were not included for analyses mainly due to the loss of the guide cannula before completion of all experimental sessions. The data for these animals were not used because their injection sites could not be verified.

\section{Chemical Agents and Vehicle}

The artificial cerebrospinal fluid (aCSF) consisted of (in $\mathrm{mM}$ ): $120.0 \mathrm{NaCl}, 4.8 \mathrm{KCl}, 1.2 \mathrm{KH}_{2} \mathrm{PO}_{4}, 1.2 \mathrm{MgSO}_{4}, 25.0$ 
$\mathrm{NaHCO}_{3}, 2.5 \mathrm{CaCl}_{2}$, and 10.0 D-glucose. Ethyl alcohol (190 proof; McCormick Distilling Co., Weston, MO), acetaldehyde (Sigma, St Louis, $\mathrm{MO}$ ), the $5-\mathrm{HT}_{3}$ receptor antagonist ICS 205-930 (Sigma), the $\mathrm{D}_{2,3}$ agonist quinpirole (Sigma), and the catalase inhibitor 3-amino-1,2,4-triazole (Sigma) were dissolved in the aCSF solution and the $\mathrm{pH}$ adjusted to $7.4 \pm 0.1$.

\section{Apparatus}

The test chambers $(30 \times 30 \times 26 \mathrm{~cm} ; w \times h \times d)$ were situated in sound-attenuating cubicles $(64 \times 60 \times 50 \mathrm{~cm}$, Coulbourn Instruments, Allentown, PA) and illuminated by a dim house light during testing. Two identical levers $(3.5 \times 1.8 \mathrm{~cm})$ were mounted on a single wall of the test chamber, $15 \mathrm{~cm}$ above a grid floor, and were separated by $12 \mathrm{~cm}$. Levers were raised to this level to avoid accidental brushing against the lever and to reduce responses as a result of general locomotor activation. Directly above each lever was a row of three different colored cue lights. The light (red) to the far right over the active bar was illuminated during resting conditions. A desktop computer equipped with an operant control system (L2T2 system, Coulbourn Instruments) recorded the data and controlled the delivery of infusate in relation to lever response.

An electrolytic microinfusion transducer system (Bozarth and Wise, 1980) was used to control infusions of drug or vehicle. Two platinum electrodes were placed in an infusatefilled gas-tight cylinder $(28 \mathrm{~mm}$ in length $\times 6 \mathrm{~mm}$ in diameter) equipped with a 28-gauge injection cannula (Plastics One, Roanoke, VA). The electrode was connected by a spring-coated cable (Plastics One) and swivel (Model 205, Mercotac, Carlsbad, CA) to a constant current generator (MNC, Shreveport, LA) that delivered $6 \mu \mathrm{A}$ of quiescent current (during resting conditions) and $200 \mu \mathrm{A}$ of infusion current (when the active lever was pressed) between the electrodes. Depression of the active lever delivered the infusion current for $5 \mathrm{~s}$, which led to the rapid generation of $\mathrm{H}_{2}$ gas (raising the pressure inside the gastight cylinder), and, in turn, forcing $100 \mathrm{nl}$ of the infusate through the injection cannula. During the 5-s infusion and additional 5-s timeout period, the house light and right cue light (red) were extinguished and the left cue light (green) over the active lever flashed on and off at 0.5-s intervals.

\section{Animal Preparation}

While under isoflurane anesthesia, subjects were prepared for stereotaxically implanting a 22-gauge guide cannula (Plastics One) into the right hemisphere; the guide cannula was aimed $1.0 \mathrm{~mm}$. above the target region. Coordinates (Paxinos and Watson, 1986) for placements into the posterior VTA were $5.4 \mathrm{~mm}$ posterior to bregma, $2.1 \mathrm{~mm}$ lateral to the midline, and $8.5 \mathrm{~mm}$ ventral from the surface of the skull at a 10-degree angle to the vertical. Coordinates for placements into the anterior VTA were $4.8 \mathrm{~mm}$ posterior to bregma, $2.1 \mathrm{~mm}$ lateral to the midline, and $8.5 \mathrm{~mm}$ ventral from the surface of the skull at a 10-degree angle to the vertical. In between experimental sessions, a 28-gauge stylet was placed into the guide cannula and extended $0.5 \mathrm{~mm}$ beyond the tip of the guide. Following surgery, rats were individually housed and allowed to recover 7-10 days.
Animals were handled for at least $5 \mathrm{~min}$ daily beginning on the fifth recovery day. Subjects were not acclimated to the experimental chambers prior to the commencement of data collection, nor did they receive any prior operant training.

\section{General Test Condition}

For testing, subjects were brought to the testing room, the cannula stylet was removed, and the injection cannula screwed into place. To avoid trapping air at the tip of the injection cannula, the infusion current was delivered for $5 \mathrm{~s}$ during insertion of the injector, which resulted in a single noncontingent administration of infusate at the beginning of the session. Injection cannulae extended $1.0 \mathrm{~mm}$ beyond the tip of the guide. The test chamber was equipped with two levers. Depression of the 'active lever' (FR1 schedule of reinforcement) caused the delivery of a 100-nl bolus of infusate over $5 \mathrm{~s}$ followed by a 5 -s time-out period. During both the 5-s infusion period and 5-s time-out period, responses on the active lever were recorded but did not produce further infusions. Responses on the 'inactive lever' did not result in infusions. The number of infusions and responses on the active and inactive lever were recorded. The assignment of active and inactive lever with respect to the left or right position was counterbalanced among subjects, and remained the same for each rat throughout the experiment. No shaping technique was used to facilitate the acquisition of lever responses. The duration of each test session was $4 \mathrm{~h}$ and sessions occurred every other day.

\section{EtOH and ACD Dose-Response in the Posterior and Anterior VTA}

For EtOH self-infusions, $\mathrm{P}$ rats, with cannulae placements in either the posterior or anterior VTA, were randomly assigned to one of four groups ( $n=6$ /group) that selfadministered artificial CSF (aCSF) for all eight sessions, or 50 and 75, or 100 and 200, or 150 and $300 \mathrm{mg} \%(17-66 \mathrm{mM})$ $\mathrm{EtOH}$ in aCSF. For the groups self-administering EtOH, the lowest concentration was available for the initial four sessions and the higher of the two concentrations was available for the last four sessions.

For ACD self-infusions, $\mathrm{P}$ rats, with cannulae placements in either the posterior or anterior VTA, were randomly assigned to one of five groups ( $n=6-7 /$ group) that selfadministered aCSF for all eight sessions, or 3 and 6 , or 11 and 23 , or 45 and 90 , or 180 and $360 \mu \mathrm{M}$ ACD in aCSF. For the groups self-administering $\mathrm{ACD}$, the lowest concentration was available for the initial four sessions and the higher of the two concentrations was available for the last four sessions.

\section{Coinfusion of 3-Amino-1,2,4-Triazole (Triazole) During Acquisition of $150 \mathrm{mg} \% \mathrm{EtOH}$}

Three groups of rats ( $n=6-8$ /group) with cannulae placements in the posterior VTA were used for this experiment. One group was given $150 \mathrm{mg} \% \mathrm{EtOH}$ to selfinfuse for eight consecutive sessions. The other groups were given $150 \mathrm{mg} \% \mathrm{EtOH}$ combined with either 8 and 16, or 32 and $64 \mathrm{mM}$ triazole. The lower concentration of triazole was 
coadministered with $150 \mathrm{mg} \%$ EtOH during the initial four sessions, and the higher concentration was coadministered during the last four sessions. A concentration of $8 \mathrm{mM}$ triazole has been shown to inhibit catalase activity over $85 \%$ in cerebral cortical homogenates (Zimatkin et al, 1998). Local administration of triazole as opposed to peripheral injection was used for a combination of reasons. Our previous success with coinfusing quinpirole (Rodd et al, $2004 \mathrm{~b}$ ) or $5-\mathrm{HT}_{3}$ antagonists (Rodd-Henricks et al, 2003) suggested that a local pharmacological effect for blocking the actions of EtOH could be obtained with this approach. Triazole is an irreversible inhibitor (reviewed in Hunt, 1996; Smith et al, 1997) and should produce progressive inhibition of intracellular catalase activity around the injection site during each of the 4-h sessions. On the other hand, the peripheral injection of triazole produces side effects (see review by Hunt, 1996) and has been demonstrated to only partially inhibit brain catalase activity (Sanchis-Segura and Aragon, 2002).

\section{Coinfusion of Quinpirole During Maintenance of Self-Administration of EtOH and ACD}

Animals were randomly assigned to one of six groups ( $n=6-7 /$ group). Three groups self-administered $150 \mathrm{mg} \%$ EtOH for the initial four sessions, $150 \mathrm{mg} \% \mathrm{EtOH}$ with 1, 10 or $100 \mu \mathrm{M}$ quinpirole during sessions 5 and 6 , and $150 \mathrm{mg} \%$ $\mathrm{EtOH}$ alone during session 7. These concentrations of quinpirole were selected because microdialysis studies indicated that local perfusion of the VTA with these concentrations reduced somatodendritic release of DA (Kohl et al, 1998) and coadministration of these concentrations of quinpirole reduced EtOH self-infusions (Rodd $e t$ al, $2004 \mathrm{~b}$ ). Three separate groups self-administered $23 \mu \mathrm{M}$ ACD for the initial four sessions, $23 \mu \mathrm{M}$ ACD with 1,10 or $100 \mu \mathrm{M}$ quinpirole during sessions 5 and 6 , and $23 \mu \mathrm{M}$ ACD alone during session 7.

\section{Coinfusion of Ics 205,930 (ICS) During Acquisition and} Maintenance of Self-Administration of EtOH and ACD

For the acquisition experiment, animals were randomly assigned to one of four groups ( $n=6-8$ /group). Separate groups coinfused either 100 or $200 \mu \mathrm{M}$ ICS with $150 \mathrm{mg} \%$ EtOH for all seven sessions. Additional groups coinfused either 100 or $200 \mu \mathrm{M}$ ICS with $23 \mu \mathrm{M}$ ACD for all seven sessions. A previous study indicated that concentrations of $100 \mu \mathrm{M}$ ICS effectively prevented the acquisition of $200 \mathrm{mg} \%$ $\mathrm{EtOH}$ by Wistar rats and also reduced the self-infusion of $200 \mathrm{mg} \%$ EtOH after it had been established (RoddHenricks et al, 2003).

For the maintenance experiment, animals were randomly assigned to one of six groups ( $n=6-8 /$ group). Three groups self-administered $150 \mathrm{mg} \% \mathrm{EtOH}$ for the initial four sessions, $150 \mathrm{mg} \%$ EtOH with 100,200 or $400 \mu \mathrm{M}$ ICS during sessions 5 and 6 , and $150 \mathrm{mg} \% \mathrm{EtOH}$ alone during session 7. Three separate groups self-administered $23 \mu \mathrm{M}$ ACD for the initial four sessions, $23 \mu \mathrm{M}$ ACD with 100,200 or $400 \mu \mathrm{M}$ ICS 205,930 during sessions 5 and 6 , and $23 \mu \mathrm{M}$ ACD alone during session 7 .

\section{Histology}

At the termination of the experiment, $1 \%$ bromophenol blue $(0.5 \mu \mathrm{l})$ was injected into the infusion site. Subsequently, the animals were given a fatal dose of Nembutal and then decapitated. Brains were removed and immediately frozen at $-70^{\circ} \mathrm{C}$. Frozen brains were subsequently equilibrated at $-15^{\circ} \mathrm{C}$ in a cryostat microtome and then sliced into $40 \mu \mathrm{m}$ sections. Sections were then stained with cresyl violet and examined under a light microscope for verification of the injection site using the rat brain atlas of Paxinos and Watson (1986).

\section{Statistical Analyses}

For the analysis of the EtOH plus triazole, and the EtOH and ACD dose-response experiments, the data from rats that self-administered aCSF throughout the eight sessions were averaged for 2 consecutive sessions (ie, sessions 1 and 2, 3 and 4, etc). This was performed to avoid the complexity of a nested design. Data analysis consisted of a treatment $\times$ session mixed ANOVA, with a repeated measure of 'session', performed on the number of infusions. Additionally, for each individual group, lever discrimination was determined by type (active or inactive) $\times$ session mixed ANOVA with a repeated measure of 'session'. An analysis of lever discrimination is needed to help distinguish between reinforcement-contingent behavior and general drug-stimulated locomotor activity. Data analysis of the effects of triazole, quinpirole and ICS 205,930 coadministration studies consisted of treatment $\times$ session mixed ANOVAs, with repeated measures of 'session', performed on the number of infusions for the acquisition experiment and active lever responses for the maintenance experiment. Post hoc comparisons were conducted with the Tukey's $b$-test.

\section{RESULTS}

The posterior VTA was defined as the VTA region at the level of the interpeduncular nucleus, coronal sections at -5.3 to $-6.0 \mathrm{~mm}$ bregma; the anterior VTA was defined as the region in coronal sections -4.8 to $-5.2 \mathrm{~mm}$ bregma (Figure 1). Cannula placements surrounding the VTA included injection sites located in the substantia nigra, interpeduncular nucleus, red nucleus, and caudal linear nucleus of the raphe. Data for these rats were not included in the statistical analyses. Cannula placements surrounding the VTA did not support ETOH self-administration (average number of active and inactive lever responses during acquisition were $8 \pm 2$ and $7 \pm 2$, respectively), which is in agreement with findings previously reported (Rodd et al, 2004b; Rodd-Henricks et al, 2000).

\section{EtOH and ACD Dose-Response in the Posterior and Anterior VTA}

EtOH concentrations between 0 and $300 \mathrm{mg} \%$ were tested to determine the response-contingent behaviors of female $\mathrm{P}$ rats with injections sites in the posterior or anterior VTA (Figure 2). Reducing the analysis to the average number of infusions received during the four sessions revealed that 


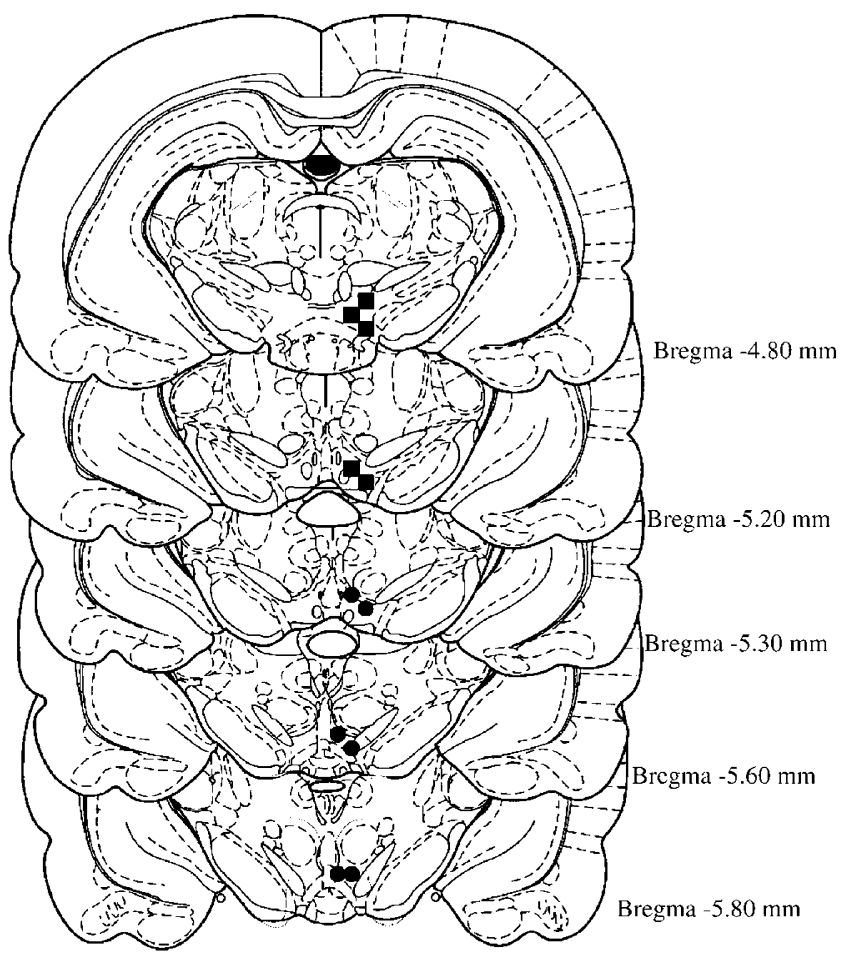

Figure I Shows representative injection sites within the anterior and posterior VTA. Squares indicate placements in the anterior VTA, and circles indicate placements in the posterior VTA. Overlapping placements are not shown. Therefore, this figure is not a quantitative representation of the injection sites.

there was a significant effect of placement $\left(\mathrm{F}_{1,70}=220.6\right.$; $p<0.0001)$, concentration $\left(\mathrm{F}_{6,70}=22.2 ; p<0.0001\right)$, and a placement $\times$ concentration interaction $\quad\left(\mathrm{F}_{6,70}=20.2\right.$; $p<0.0001)$. In rats with injection tips located within the posterior VTA, there was a significant effect of EtOH concentration $\left(\mathrm{F}_{6,35}=26.6 ; p<0.0001\right)$, with post hoc comparisons (Tukey's $b ; p<0.05$ ) indicating that $\mathrm{P}$ rats given $75,100,150,200$ or $300 \mathrm{mg} \% \mathrm{EtOH}$ received significantly more infusions than rats given 0 or $50 \mathrm{mg} \%$ EtOH (Figure 2). Additionally, post hoc comparisons indicated that rats self-administering 100,150 or $200 \mathrm{mg} \%$ EtOH received more infusions than rats self-administering $300 \mathrm{mg} \% \mathrm{EtOH}$. In contrast to the posterior VTA data, $50-300 \mathrm{mg} \%$ concentrations of EtOH were not significantly self-infused into the anterior VTA (Group: $\mathrm{F}_{6,35}=0.57$; $p=0.79)$.

Throughout the sessions, the number of lever presses by the aCSF control animals with injector placements within the posterior or anterior VTA did not differ ( $p$-values $>0.59$ ) between the active and inactive bar (data not shown). $\mathrm{P}$ rats self-administering $75,100,150,200$ and $300 \mathrm{mg} \% \mathrm{EtOH}$ into the posterior VTA discriminated between the active and inactive lever (data not shown, but all $p$-values $<0.05$ ). In contrast, $\mathrm{P}$ rats self-administering EtOH into the anterior portion of the VTA did not discriminate between the active and inactive levers ( $p$ values $>0.19$ ) and had low levels of responding on both levers (less than 20 responses/session), which were comparable to responses observed with aCSF in either the anterior or posterior VTA.

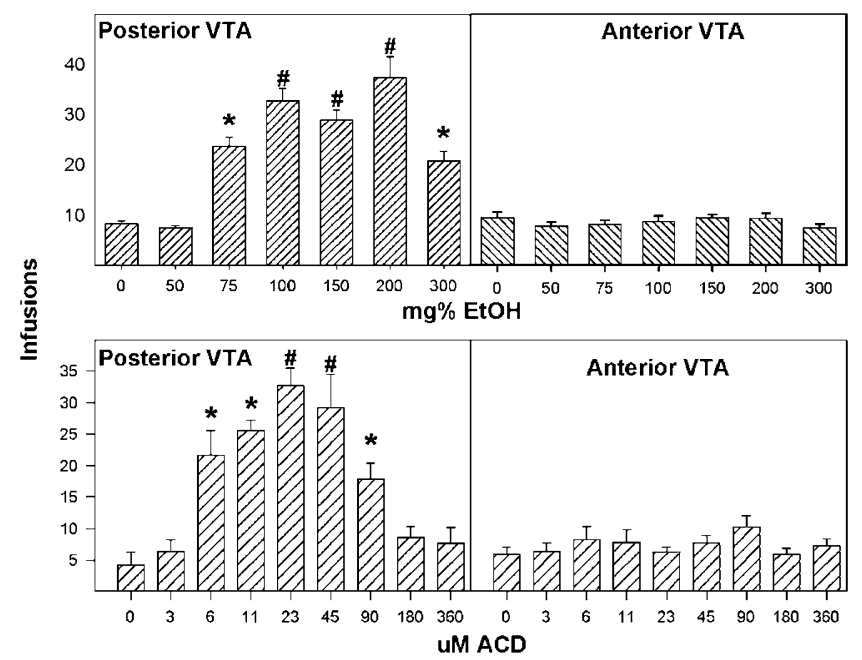

Figure 2 Average infusions across the four acquisition sessions for the self-administration of (a) 0-300 mg\% ethanol (EtOH) into the posterior and anterior VTA (top panels; $n=6 /$ dose for each subregion), and (b) 0 $60 \mu \mathrm{M}$ acetaldehyde (ACD) into the posterior and anterior VTA (bottom panels; $n=6 /$ dose for each subregion). $*$ Indicates that number of infusions is significantly $(p<0.05)$ higher than infusions of (a) 0 and $50 \mathrm{mg} \% \mathrm{EtOH}$, or (b) $0,3,180$ and $360 \mu \mathrm{M}$ ACD. "Indicates that number of infusions is significantly $(p<0.05)$ higher than (a) 0,50 and $300 \mathrm{mg} \% \mathrm{EtOH}$, or (b) 0, 3 , 90, 180 and $360 \mu$ M ACD. Data are the means \pm SEM.

ACD concentrations between 3 and $360 \mu \mathrm{M}$ were tested in the present study to determine the response-contingent behaviors of female $\mathrm{P}$ rats with injection sites in the posterior or anterior VTA. Reducing the analysis to the average number of infusions received during the four sessions (Figure 2, bottom) revealed that there was a significant effect of placement $\left(\mathrm{F}_{1,111}=88.9 ; p<0.0001\right)$, concentration $\left(\mathrm{F}_{8,111}=17.6 ; \quad p<0.0001\right)$, and a placement $\times$ concentration interaction $\left(\mathrm{F}_{8,111}=8.7 ; p<0.0001\right)$. In rats with injection tips located within the posterior VTA, there was a significant effect of ACD concentration $\left(\mathrm{F}_{8,55}=\right.$ 39.4; $p<0.0001$ ), with post hoc comparisons (Tukey's $b$; $p<0.05$ ) indicating that $\mathrm{P}$ rats given $6,11,23,45$ or $90 \mu \mathrm{M}$ ACD received significantly more infusions than rats given 0 , 3, 180 or $360 \mu \mathrm{M} \mathrm{ACD} \mathrm{(Figure} \mathrm{2).} \mathrm{Additionally,} \mathrm{post} \mathrm{hoc}$ comparisons indicated that rats self-administering 23 or $45 \mu \mathrm{M}$ ACD received more infusions than rats self-administering $90 \mu \mathrm{M} \mathrm{ACD}$. In contrast to the posterior VTA data, none of the concentrations of $\mathrm{ACD}$ were significantly self-infused into the anterior VTA (Group: $\mathrm{F}_{8,56}=0.54$; $p=0.82$ ).

Lever discrimination was never observed in $\mathrm{P}$ rats selfadministering ACD into the anterior VTA (data not shown, but all $p$-values $>0.27$ ), or in P rats self-administering 0,3 , 180 or $360 \mu \mathrm{M}$ ACD into the posterior VTA (data not shown, but all $p$-values $>0.09$ ). However, lever discrimination was observed in P rats self-administering 6,11,23, 45 or $90 \mu \mathrm{M}$ $\mathrm{ACD}$ in the posterior VTA (data not shown, but all $p$ values $<0.05)$.

\section{Effects of Triazole on the Self-Infusion of EtOH}

$\mathrm{P}$ rats readily self-administer $150 \mathrm{mg} \% \mathrm{EtOH}$ into the posterior VTA and learn to discriminate the active from 
the inactive lever by the second session; responding on the active lever is maintained from session 2 through session 8 (Figure 3). Coinfusion of 8 or $32 \mathrm{mM}$ triazole in the first four sessions, or 16 or $64 \mathrm{mM}$ triazole in the second four sessions had no significant effect on responding on the active lever for the self-infusion of $150 \mathrm{mg} \% \mathrm{EtOH}$ (Figure 3; only 8 and $16 \mathrm{mM}$ triazole data are shown; higher triazole concentrations gave similar results). Although responses on the active lever for $150 \mathrm{mg} \% \mathrm{EtOH}$ in the presence of $16 \mathrm{mM}$ triazole was slightly lower than for EtOH alone (50 vs 60 responses averaged across sessions), this difference was not statistically different. Moreover, a one-way ANOVA performed on the average number of infusions received for the last three sessions revealed no significant effects of triazole coadministration on EtOH self-infusion $\left(\mathrm{F}_{4,29}=0.3\right.$; $p=0.88)$.

\section{Coinfusion of Quinpirole During Maintenance of Self-Infusion of EtOH and ACD}

Rats readily acquired $150 \mathrm{mg} \% \mathrm{EtOH}$ and $23 \mu \mathrm{M}$ ACD selfadministration into the posterior VTA within the first four acquisition sessions and discriminated the active from the inactive lever during sessions 2-4 (Figure 4). Coadministration of 1 or $10 \mu \mathrm{M}$ quinpirole did not alter either EtOH or ACD self-administration (data not shown, but all F values $_{2,10}<2.3$; all $p$ values $>0.15$ ). However, coadministration of $100 \mu \mathrm{M}$ quinpirole during sessions 5 and 6 reduced EtOH and ACD self-infusion and reduced responses on the active lever to levels observed on the inactive lever (Figure 4; for active lever responses in session $4 v \mathrm{~s}$ sessions 5 and 6 , all $\mathrm{F}$ values ${ }_{2,10}>12.3$; all $p$-values $<0.002$ ). During session 7, when EtOH and ACD alone were given, $\mathrm{P}$ rats reinstated responding on the active lever (all $\mathrm{F}$ values $_{2,12}>14.6$; all $p$-values $<0.001$ for session $7 v s$ sessions 5 and 6 ) to levels observed in session 4 .

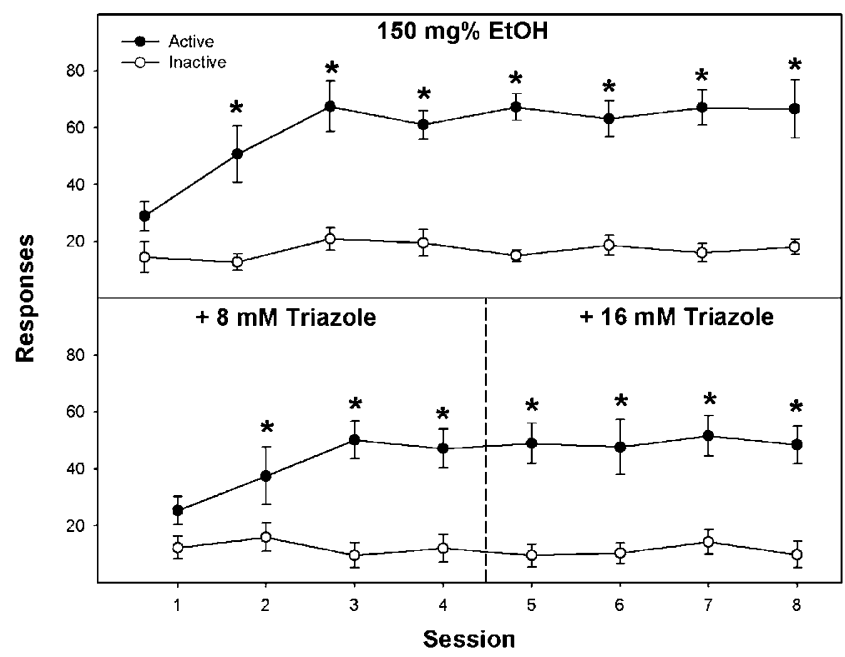

Figure 3 Responses on the active and inactive lever for $\mathrm{P}$ rats selfadministering $150 \mathrm{mg} \%$ ethanol $(\mathrm{EtOH})$ alone for eight sessions $(n=6)$ or coadministering $150 \mathrm{mg} \% \mathrm{EtOH}$ plus 8 or $16 \mathrm{mM} 3$-amino-1,2,4-triazole (Triazole; $n=8$ ) into the posterior VTA. Data are the means \pm SEM. *Indicates that responses on the active lever are significantly $(p<0.05)$ higher than responses on the inactive lever for that session.

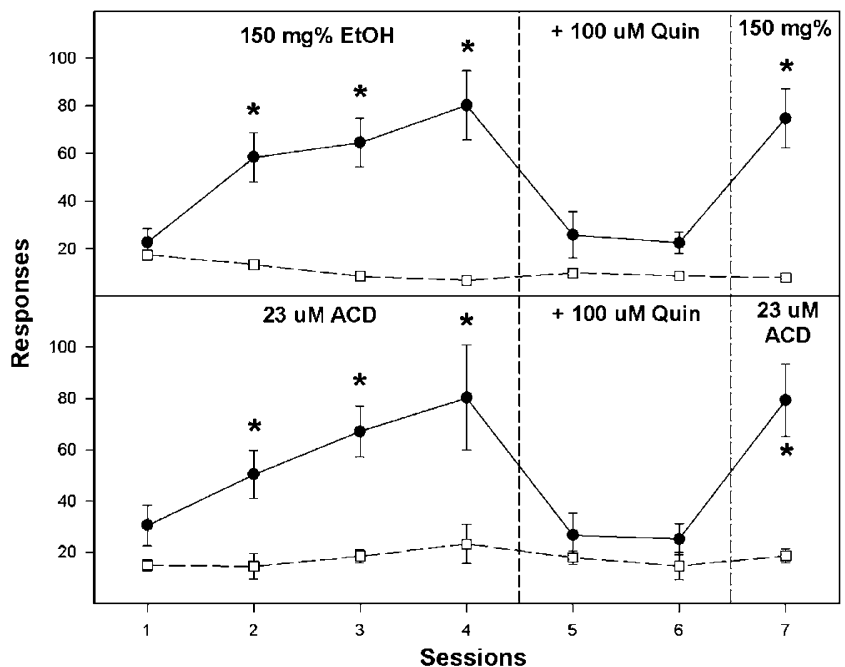

Figure 4 Responses on the active and inactive levers for the self-infusion of $150 \mathrm{mg} \%$ ethanol (EtOH; top panel; $n=6$ ) or $23 \mu \mathrm{M}$ acetaldehyde (ACD; bottom panel; $n=7$ ) during (a) the first four sessions, (b) coinfusion with $100 \mu \mathrm{M}$ quinpirole (Quin) in sessions 5 and 6 , and (c) ethanol or ACD alone in session 7. Data are the means \pm SEM. * Indicates that responses on the active lever were significantly $(p<0.05)$ higher than responses on the inactive lever for that session.

\section{Coinfusion of ICS 205,930 (ICS) During Acquisition and Maintenance of Self-Infusion of EtOH and ACD}

Coadministration of $100 \mu \mathrm{M}$ ICS did not alter the acquisition (Figure 5, top panel) or maintenance (data not shown) of $150 \mathrm{mg} \% \mathrm{EtOH}$ self-administration into the posterior VTA by P rats, as indicated by the significantly higher responses on the active $v s$ the inactive lever. However, coadministration of $200 \mu \mathrm{M}$ ICS prevented the acquisition (Figure 5, middle panel) and maintenance (Figure 5, bottom panel) of $150 \mathrm{mg} \% \mathrm{EtOH}$ self-administration by $\mathrm{P}$ rats. The effect of ICS on maintenance of EtOH self-infusion was reversible, because $\mathrm{P}$ rats reinstated responding on the active lever when $150 \mathrm{mg} \% \mathrm{EtOH}$ alone was given in session 7 (Figure 5, bottom panel). In contrast, coadministration of 100 or $200 \mu \mathrm{M}$ ICS did not inhibit the acquisition of $23 \mu \mathrm{M}$ ACD self-administration into the posterior VTA (Figure 6, top panel shows results for $200 \mu \mathrm{M}$ ICS). P rats selfadministering $23 \mu \mathrm{M}$ ACD with either 100 or $200 \mu \mathrm{M}$ ICS discriminated between the active and inactive levers for all seven sessions $(p$-values $<0.026)$. For the maintenance experiment, during sessions $2-4$, rats readily self-infused $23 \mu \mathrm{M} \mathrm{ACD}$ and discriminated the active from the inactive lever (Figure 6, middle and bottom panels; all $p$-values $<0.05)$. However, coadministration of 200 or $400 \mu \mathrm{M}$ ICS (Figure 6, middle and bottom panels) did not alter responding on the active lever (all $\mathrm{F}$ values $_{2,10}<0.9$; all $p$-values $>0.44$ for sessions 5 and $6 v s$ session 4 ).

\section{DISCUSSION}

The major findings of this study indicate that EtOH and ACD can independently produce reinforcing effects within the posterior, but not anterior, VTA, and these reinforcing effects are mediated through VTA-DA neuronal activity. However, the mechanisms underlying the reinforcing effects 


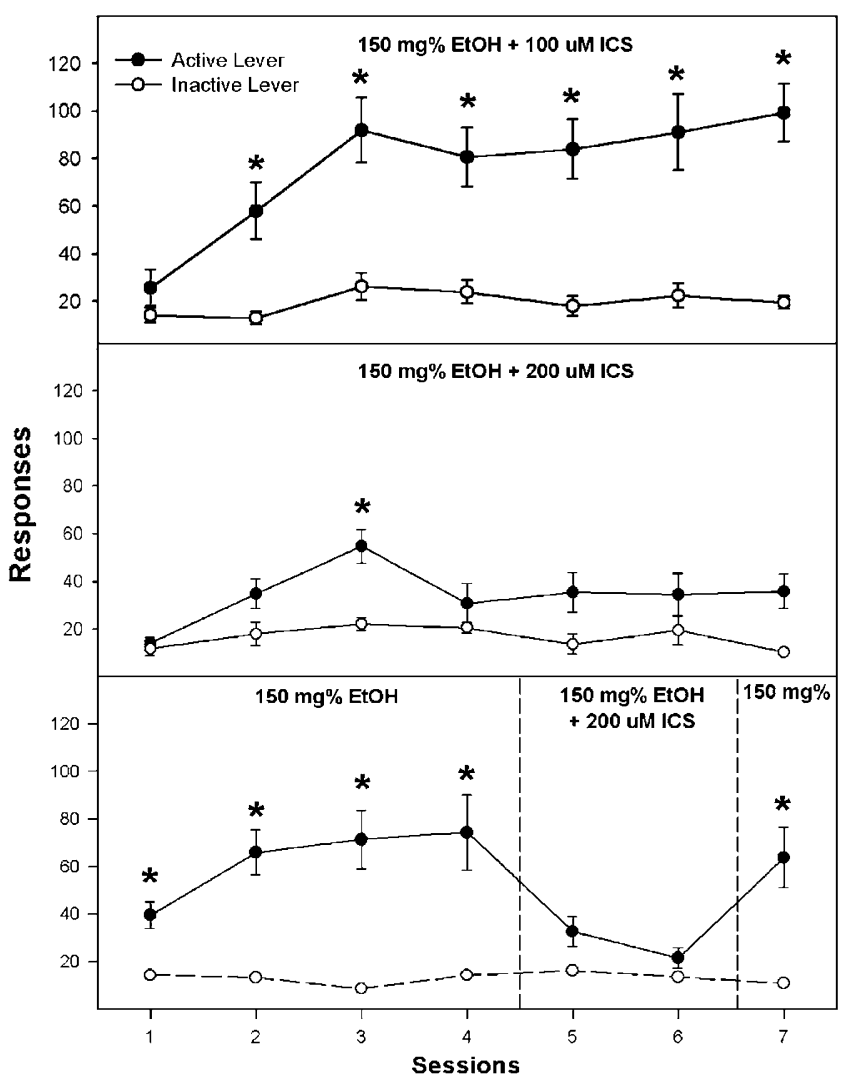

Figure 5 Effects of I00 and $200 \mu$ M ICS 205,930 (ICS) on responses on the active and inactive levers for the self-infusion of $150 \mathrm{mg} \%$ ethanol $(\mathrm{EtOH})$ into the posterior VTA by $\mathrm{P}$ rats during acquisition (top and middle panels), and maintenance (bottom panel). For the acquisition experiment, ICS was coadministered throughout all seven sessions. For the maintenance experiment, ICS was coinfused only during sessions 5 and 6 . Data are the means \pm SEM ( $n=6-7 /$ group). * Indicates that responses on the active lever are significantly $(p<0.05)$ higher than responses on the inactive lever for that session.

of EtOH and ACD in the posterior VTA appear to be different, with $5-\mathrm{HT}_{3}$ receptors contributing to the reinforcing effects of EtOH, but not ACD. The finding that the acquisition and maintenance of self-infusion of $150 \mathrm{mg} \%$ EtOH into the posterior VTA was blocked by ICS (Figure 5), whereas the self-administration of $23 \mu \mathrm{M} \mathrm{ACD}$ was unaffected by coinfusion with ICS at concentrations as high as $400 \mu \mathrm{M}$ (Figure 6) supports an interpretation that $\mathrm{EtOH}$ and $\mathrm{ACD}$ are independently producing reinforcing effects within the posterior VTA. If formation of ACD was underlying the reinforcing effects of EtOH within the posterior VTA then coadministration of the $5-\mathrm{HT}_{3}$ receptor antagonist should have blocked the effects of both EtOH and ACD.

An attempt was made to determine if the formation of ACD was contributing to the reinforcing effects of EtOH within the posterior VTA, using the coinfusion of the catalase inhibitor triazole with EtOH (Figure 3). The concentrations of triazole used (8-64 mM) have been shown to inhibit catalase activity by $85 \%$ or more in brain homogenates (Zimatkin et al, 1998). However, the formation of ACD was reduced only $60 \%$ in brain homogenates in the presence of $8 \mathrm{mM}$ triazole (Zimatkin et al, 1998), indicating other (unknown) metabolic pathways are apparently involved in the production of ACD. Furthermore, in

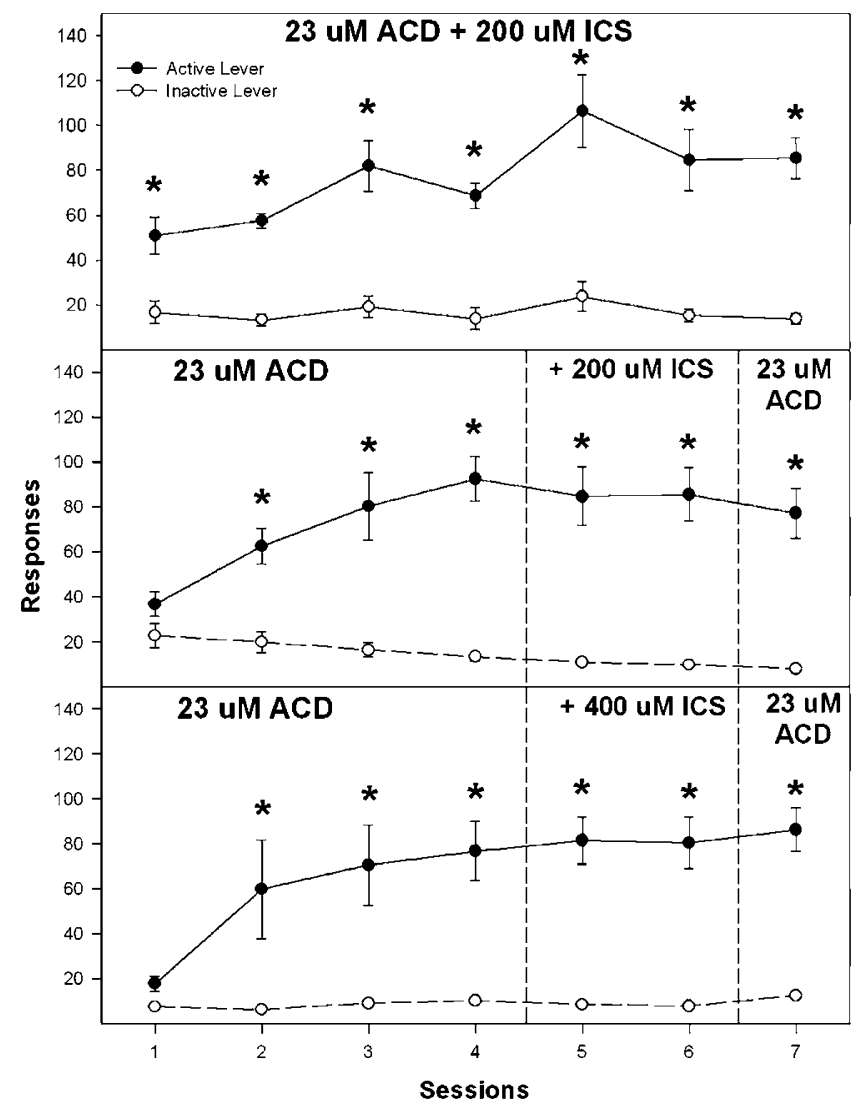

Figure 6 Effects of 200 and $400 \mu$ M ICS 205,930 (ICS) on responses on the active and inactive levers for the self-infusion of $23 \mu \mathrm{M}$ acetaldehyde (ACD) into the posterior VTA by $\mathrm{P}$ rats during acquisition (top panel), and maintenance (middle and bottom panels). For the acquisition experiment, ICS was coadministered throughout all seven sessions. For the maintenance experiment, ICS was coinfused only during sessions 5 and 6 . Data are the means \pm SEM ( $n=6-8 /$ group). * Indicates that responses on the active lever are significantly $(p<0.05)$ higher than responses on the inactive lever for that session.

vivo administration of triazole only partially inhibits brain catalase activity (Sanchis-Segura and Aragon, 2002). Therefore, a direct measure of catalase activity, following coadministration of triazole or other inhibitor, is needed to determine the effectiveness of the treatment. Furthermore, significant amounts of ACD can be generated even when catalase activity is almost completely inhibited (Zimatkin et al, 1998). Therefore, the results from the present triazole experiment are inconclusive regarding whether the local formation of ACD could be contributing to the reinforcing actions of EtOH within the posterior VTA. Future studies to resolve this issue will need to use better pharmacological tools that are more effective in inhibiting the conversion of EtOH to ACD within the brain.

The finding that the $5-\mathrm{HT}_{3}$ receptor antagonist prevented the acquisition of EtOH self-infusion and reduced the self-administration of EtOH by $\mathrm{P}$ rats after it had been established is in agreement with findings for Wistar rats (Rodd-Henricks et al, 2003). However, with Wistar rats, a concentration of $50 \mu \mathrm{M}$ ICS prevented the acquisition and blocked the maintenance of $200 \mathrm{mg} \%$ EtOH self-infusion into the posterior VTA (Rodd-Henricks et al, 2003), whereas a $100 \mu \mathrm{M}$ concentration of ICS was without effect 
in the $\mathrm{P}$ rat (Figure 5). These results suggest that there may be differences in the $5-\mathrm{HT}_{3}$ receptor systems in the posterior VTA between $\mathrm{P}$ and Wistar rats. The requirement for a higher concentration of ICS to effectively reduce EtOH selfinfusion could also indicate that $\mathrm{EtOH}$ may be more reinforcing in the posterior VTA of $\mathrm{P}$ than Wistar rats. A recent study, comparing the reinforcing effects of EtOH in the posterior VTA of $\mathrm{P}$ and Wistar rats, found that the posterior VTA of $\mathrm{P}$ rats, compared to Wistar rats, is more sensitive to the reinforcing effects of EtOH (Rodd et al, 2004a).

At the $\mu \mathrm{M}$ concentrations used, there is evidence that the ICS compound can act at the $\mathrm{GABA}_{\mathrm{A}}$ receptor (Klein et al, 1994). However, a previous study demonstrated that $\mu \mathrm{M}$ concentrations of two other $5-\mathrm{HT}_{3}$ antagonists (ie LY-278584 and zacopride) also produced similar effects on the selfinfusion of EtOH into the posterior VTA by Wistar rats (Rodd-Henricks et al, 2003). LY-278-584 is approximately 25 -fold less potent than ICS at the $\mathrm{GABA}_{\mathrm{A}}$ receptor, and zacopride at $\mathrm{mM}$ concentrations had no apparent effect at the $\mathrm{GABA}_{\mathrm{A}}$ receptor (Klein et al, 1994). Therefore, these findings support the idea that ICS is reducing EtOH selfadministration by inhibiting $5-\mathrm{HT}_{3}$ receptors. This could occur by ICS reducing the excitatory tone exhibited by 5 $\mathrm{HT}_{3}$ receptors on DA neurons within the VTA (Campbell et al, 1996; Minabe et al, 1991; Rasmussen et al, 1991), and/ or blocking the excitatory action of $\mathrm{EtOH}$ at $5-\mathrm{HT}_{3}$ receptors (Lovinger and White, 1991; Sung et al, 2000).

The present results indicate that coinfusion of $150 \mathrm{mg} \%$ $\mathrm{EtOH}$ with $100 \mu \mathrm{M}$ quinpirole, a $\mathrm{D}_{2,3}$ receptor agonist, reduced the self-infusion of $\mathrm{EtOH}$ (Figure 4). This concentration of quinpirole should activate cell body $\mathrm{D}_{2}$ autoreceptors and reduce DA neuronal activity (Congar et al, 2002; Jeziorski and White, 1989). These results with $\mathrm{P}$ rats are similar to findings reported for Wistar rats (Rodd et al, 2004b) and suggest that activation of DA neurons is involved in mediating the reinforcing effects of $\mathrm{EtOH}$ within the posterior VTA. In addition, the present findings (Figure 4) suggest that activation of DA neurons in the posterior VTA is also involved in mediating the reinforcing effects of ACD in this region. A recent electrophysiological study (Foddai et al, 2004), indicating that ACD increases DA neuronal activity in the VTA, supports an interpretation that activation of DA neurons is involved in mediating the reinforcing effects of ACD in the posterior VTA.

Previous studies indicated that $150-300 \mathrm{mg} \%$ EtOH was self-infused into the posterior, but not anterior, VTA of Wistar rats (Rodd-Henricks et al, 2000). The present results indicate a similar subregional heterogeneity for $\mathrm{EtOH}$ selfadministration exists between the anterior and posterior VTA of $\mathrm{P}$ rats (Figure 2). Moreover, the self-infusion of ACD by $\mathrm{P}$ rats exhibits subregional heterogeneity similar to that observed for EtOH between the anterior and posterior VTA (Figure 2). In addition, ACD appears to be a 1000-fold more potent reinforcer than EtOH in the posterior VTA, a finding that is in agreement with previous results when data for Wistar and P rats were compared (Rodd-Henricks et al, $2000,2002 \mathrm{~b})$. In vitro studies indicated that $45-225 \mathrm{mg} \%$ $\mathrm{EtOH}$ could generate up to $4 \mathrm{nmol} / \mathrm{mg}$ tissue wet $\mathrm{wt} / \mathrm{h}$ of ACD (approximately $4 \mu \mathrm{M}$ ACD). These brain EtOH concentrations could be attained by $\mathrm{P}$ rats under a variety of self-administration conditions (Murphy et al, 1986;
Rodd-Henricks et al, 2001; Waller et al, 1984), and produce brain levels of ACD that are within a range that is reinforcing (Figure 2).

$\mathrm{P}$ rats learn to discriminate the active from the inactive lever by the second acquisition session for either $\mathrm{EtOH}$, at concentrations greater than $50 \mathrm{mg} \%$, or ACD, at concentrations greater than $3 \mu \mathrm{M}$ (Figure 4). Animals used in the present study had no previous experience in the operant chambers. This rapid learning is in agreement with several studies in which the self-infusion of EtOH (Gatto et al, 1994; Rodd-Henricks et al, 2000, 2003), opioids (Bozarth and Wise, 1981; Devine and Wise, 1994), and $\mathrm{GABA}_{\mathrm{A}}$ antagonists (Ikemoto et al, 1997b) into the VTA, or $\mathrm{D}_{1}-\mathrm{D}_{2}$ agonists (Ikemoto et al, 1997a) or cocaine (Rodd-Henricks et al, 2002a) into the shell of the nucleus accumbens were examined. The mechanisms underlying this rapid learning process are unknown but may be related to activation of the mesolimbic DA system produced by direct self-infusion of these agents.

A major concern with the ICSA technique is that diffusion away from the target site may be producing the selfadministration effects. There is no doubt that diffusion occurs with the present experimental approach. However, with the small volumes injected, diffusion away from the target site does not appear to contribute to the self-infusion behavior observed with EtOH and ACD. The observation that injection sites adjacent to the posterior VTA did not elicit ICSA behavior in the present study (Figure 2) or in previous studies (Rodd-Henricks et al, 2000, 2002b) supports this conclusion. Moreover, previous studies with this ICSA procedure also indicated that sites adjacent to the target site did not elicit self-administration behavior (Ikemoto et al, 1997a,b; Rodd et al, 2003). These results suggest that diffusion to other sites is not contributing to the observed self-infusion behavior, with the injection volumes used and at the concentrations tested.

In summary, the present findings suggest that EtOH and ACD can produce independent reinforcing effects within the posterior VTA, which involve activation of local DA neurons. In addition, activation of local $5-\mathrm{HT}_{3}$ receptors appears to be involved in mediating the reinforcing effects of EtOH, but not ACD, in the posterior VTA of the $P$ line of rats.

\section{ACKNOWLEDGEMENTS}

Supported in part by NIAAA Grants AA07611, AA12262 and AA14437.

\section{REFERENCES}

Aragon CMG, Amit Z (1992). The effect of 3-amino-1,2,4-triazole on voluntary ethanol consumption: evidence for brain catalase involvement in the mechanism of action. Neuropharmacology 31: 709-712.

Aragon CMG, Abitbol M, Amit Z (1986). Acetaldehyde may mediate reinforcement and aversion produced by ethanol. An examination using a conditioned taste-aversion paradigm. Neuropharmacology 25: 79-83.

Aragon CMG, Rogan R, Amit Z (1992). Ethanol metabolism in rat brain homogenates by a catalase- $\mathrm{H}_{2} \mathrm{O}_{2}$ system. Biochem Pharmacol 44: 93-98. 
Bozarth MA, Wise RA (1980). Electrolytic microinfusion transducer system: an alternative method of intracranial drug application. J Neurosci Methods 2: 273-275.

Bozarth MA, Wise RA (1981). Intracranial self-administration of morphine into the ventral tegmental area in rats. Life Sci 28: 551-555.

Brown ZW, Amit Z, Rockman GE (1979). Intraventricular selfadministration of acetaldehyde, but not ethanol, in naive laboratory rats. Psychopharmacology 64: 271-276.

Campbell AD, Kohl RR, McBride WJ (1996). Serotonin-3 receptor and ethanol-stimulated somatodendritic dopamine release. Alcohol 13: 569-574.

Cohen G, Sinet PM, Heikkila R (1980). Ethanol oxidation by rat brain in vivo. Alcohol Clin Exp Res 4: 366-370.

Congar P, Bergevin A, Trudeau LE (2002). D2 receptors inhibit the secretory process downstream from calcium influx in dopaminergic neurons: implication of $\mathrm{K}+$ channels. J Neurophysiol 87: 1046-1056.

Devine DP, Wise RA (1994). Self-administration of morphine, DAMGO, and DPDPE into the ventral tegmental area of rats. J Neurosci 14: 1978-1984.

Foddai M, Dosia G, Spiga S, Diana M (2004). Acetaldehyde increases dopaminergic neuronal activity in the VTA. Neuropsychopharmacology 29: 530-536.

Gatto GJ, McBride WJ, Murphy JM, Lumeng L, Li T-K (1994). Ethanol self-infusion into the ventral tegmental area by alcoholpreferring rats. Alcohol 11: 557-564.

Gill K, Menez JF, Lucas D, Deitrich RA (1992). Enzymatic production of acetaldehyde from ethanol in rat brain tissue. Alcohol Clin Exp Res 16: 910-915.

Hamby-Mason R, Chen JJ, Schenker S, Perez A, Henderson GI (1997). Catalase mediates acetaldehyde formation from ethanol in fetal and neonatal rat brain. Alcohol Clin Exp Res 21: 1063-1072.

Hunt WA (1996). Role of acetaldehyde in the actions of ethanol on the brain - A review. Alcohol 13: 147-151.

Ikemoto S, Glazier BS, Murphy JM, McBride WJ (1997a). Role of dopamine D-1 and D-2 receptors in the nucleus accumbens in mediating reward. J Neurosci 17: 8580-8585.

Ikemoto S, Murphy JM, McBride WJ (1997b). Self-infusion of GABA-A antagonists into the ventral tegmental area and adjacent regions. Behav Neurosci 111: 369-380.

Jeziorski M, White FJ (1989). Dopamine agonists at repeated 'autoreceptor-selective' doses: effects upon the sensitivity of A10 dopamine autoreceptors. Synapse 4: 267-280.

Klein RL, Sanna E, McQuilkin SJ, Whiting PJ, Harris RA (1994). Effects of 5-HT3 receptor antagonists on binding and function of mouse and human GABA-A receptors. Eur J Pharmacol 268: 237-246.

Koechling UM, Amit Z (1994). Effects of 3-amino-1,2,4-triazole on brain catalase in the mediation of ethanol consumption in mice. Alcohol 11: 235-239.

Kohl RR, Katner JS, Chernet E, McBride WJ (1998). Ethanol and negative feedback regulation of mesolimbic dopamine release in rats. Psychopharmacology 139: 79-85.

Koob GF, Roberts AJ, Schulteis G, Parsons LH, Heyser CJ, Hyytia P et al (1998). Neurocircuitry targets in ethanol: reward and dependence. Alcohol Clin Exp Res 22: 3-9.

Lovinger DM, White G (1991). Ethanol potentiation of 5-hydroxytryptamine-3 receptor-mediated ion current in neuroblastoma cells and isolated adult mammalian neurons. Mol Pharmacol 40: 263-270.

Minabe Y, Ashby CR, Schwartz JE, Wang RY (1991). The 5-HT3 receptor antagonists LY277359 and granisetron potentiate the suppressant actions of apomorphine on the basal firing rate of ventral tegmental dopamine cells. Eur J Pharmacol 209: 143-150.
Murphy JM, Gatto GJ, Waller MB, McBride WJ, Lumeng L, Li T-K (1986). Effects of scheduled access on ethanol intake by the alcohol-preferring P line of rats. Alcohol 3: 331-336.

Paxinos G, Watson C (1986). The Rat Brain in Stereotaxic Coordinates. Academic Press: New York.

Rasmussen K, Stockton ME, Czachura JF (1991). The 5-HT3 receptor antagonist zatosetron decreases the number of spontaneously active A10 dopamine neurons. Eur J Pharmacol 205: 113-116.

Rodd ZA, Bell RL, Melendez RI, Kuc KA, Lumeng L, Li T-K et al (2004a). Comparison of intracranial self-administration of ethanol within the posterior ventral tegmental area between alcohol-preferring (P) and Wistar rats. Alcohol Clin Exp Res 28: 1212-1219.

Rodd ZA, Bell RL, Zhang Y, Goldstein A, Zaffaroni A, McBride WJ et al (2003). Salsolinol produces reinforcing effects in the nucleus accumbens shell of alcohol-preferring (P) rats. Alcohol Clin Exp Res 27: 440-449.

Rodd ZA, Melendez RI, Bell RL, Kuc KA, Zhang Y, Murphy JM et al (2004b). Intracranial self-administration of ethanol within the ventral tegmental area of male Wistar rats: evidence for regional heterogeneity and involvement of dopamine neurons. J Neurosci 24: 1050-1057.

Rodd-Henricks ZA, Bell RL, Kuc KA, Murphy JM, McBride WJ, Lumeng L et al (2001). Effects of concurrent access to multiple ethanol concentrations and repeated deprivations on alcohol intake of alcohol-preferring rats. Alcohol Clin Exp Res 25: 1140-1150.

Rodd-Henricks ZA, McKinzie DL, Crile RS, Murphy JM, McBride WJ (2000). Regional heterogeneity for the intracranial selfadministration of ethanol within the ventral tegmental area of female Wistar rats. Psychopharmacology 149: 217-224.

Rodd-Henricks ZA, McKinzie DL, Li T-K, Murphy JM, McBride WJ (2002a). Cocaine is self-administered into the shell, but not the core, of the nucleus accumbens of Wistar rats. J Pharmacol Exp Ther 303: 1216-1226.

Rodd-Henricks ZA, McKinzie DL, Melendez RI, Berry N, Murphy JM, McBride WJ (2003). The effects of serotonin-3 receptor antagonists on the intracranial self-administration of ethanol into the posterior VTA of Wistar rats. Psychopharmacology 165: 252-259.

Rodd-Henricks ZA, Melendez RI, Zaffaroni A, Goldstein A, McBride WJ, Li T-K (2002b). The reinforcing effects of acetaldehyde in the posterior ventral tegmental area of alcohol-preferring rats. Pharmacol Biochem Behav 72: 55-64.

Sanchis-Segura C, Aragon CM (2002). Brain catalase inhibition blocks ethanol-related decrease of blood luteinizing hormone levels in mice. Alcohol Clin Exp Res 26: 1275-1280.

Sippel HW (1974). The acetaldehyde content in rat brain during ethanol metabolism. J Neurochem 23: 451-452.

Smith BR, Amit Z, Splawinsky J (1984). Conditioned place preference induced by intraventricular infusions of acetaldehyde. Alcohol 1: 193-195.

Smith BR, Aragon CM, Amit Z (1997). Catalase and the production of brain acetaldehyde: a possible mediator for the psychopharmacological effects of ethanol. Addict Biol 2: 277-289.

Sung KW, Engel SR, Allan AM, Lovinger DM (2000). 5-HT3 receptor function and potentiation by alcohols in frontal cortex neurons from transgenic mice overexpressing the receptor. Neuropharmacology 39: 2346-2351.

Waller MB, McBride WJ, Gatto GJ, Lumeng L, Li T-K (1984). Intragastric self-infusions of ethanol by the P and NP (alcoholpreferring and -non-preferring) lines of rats. Science 225: 78-80. Zimatkin SM (1991). Histochemical study of aldehyde dehydrogenase in the rat CNS. J Neurochem 56: 1-11.

Zimatkin SM, Liopo AV, Deitrich RA (1998). Distribution and kinetics of ethanol metabolism in rat brain. Alcohol Clin Exp Res 22: $1623-1627$ 